Etnográfica

Revista do Centro em Rede de Investigação em

Antropologia

vol. $14(2) \mid 2010$

Vol. $14(2)$

\title{
A antropologia e o estudo do consumo: revisão crítica das suas relações e possibilidades
}

The anthropology and the study of consumption: critical review of their relations and possibilities

\section{Alice Duarte}

\section{(2) OpenEdition}

\section{Journals}

Edição electrónica

URL: https://journals.openedition.org/etnografica/329

DOI: $10.4000 /$ etnografica.329

ISSN: 2182-2891

\section{Editora}

Centro em Rede de Investigação em Antropologia

\section{Edição impressa}

Data de publição: 1 junho 2010

Paginação: 363-393

ISSN: 0873-6561

\section{Refêrencia eletrónica}

Alice Duarte, «A antropologia e o estudo do consumo: revisão crítica das suas relações e possibilidades», Etnográfica [Online], vol. 14 (2) | 2010, posto online no dia 17 outubro 2011 , consultado o 10 fevereiro 2022. URL: http://journals.openedition.org/etnografica/329 ; DOI: https:// doi.org/10.4000/etnografica.329

\section{(c) (i) (8)}

Etnográfica is licensed under a Creative Commons Attribution-NonCommercial 4.0 International License. 


\title{
A antropologia e o estudo do consumo: revisão crítica das suas relações e possibilidades
}

\begin{abstract}
Alice Duarte
O artigo começa por situar temporalmente a emergência do consumo como área concreta de investigação antropológica, procurando expor os condicionalismos que dificultaram a afirmação de uma antropologia do consumo. Depois, seguindo as etapas de desenvolvimento dessa área de estudos, apresenta uma síntese selectiva de autores e obras que, de um ou outro modo, concretizam a mudança no sentido de um efectivo interesse no estudo do consumo.
\end{abstract}

PALAVRAS-CHAVE: antropologia do consumo, revisão crítica, Mauss, Marx, teorias do consumo, regimes de consumo.

DANIEL MILLER, DE MODO RECORRENTE (1987, 1995B, 1995C), REFERE os trabalhos de Douglas e Isherwood (1978) e Bourdieu (1979) como constituindo os marcos virtuais do nascimento da antropologia do consumo. Sem pôr em causa tais referências, importa questionar as razões de tão tardio desenvolvimento desta área de pesquisa. Ou, dito de outro modo, perceber o porquê de o consumo ter sido negligenciado durante tanto tempo pela antropologia.

\section{A NEGLIGÊNCIA DO CONSUMO}

Não pode haver dúvidas, por um lado, de que a expansão do consumo e dos bens de massa antecedeu a emergência da antropologia moderna e, por outro lado, de que era possível encontrar tópicos de estudo como sistemas de troca, esferas de troca, bens de prestígio ou moeda primitiva em pesquisas antropológicas diversas desde as primeiras décadas do século XX. Porquê, então, nenhuma daquelas temáticas ter levado à constituição de uma área de estudo diferenciada e consolidada que traduzisse um interesse explícito e sustentado 
pelo consumo? Um primeiro conjunto de motivos relaciona-se com o facto de os estudos antropológicos se desenvolverem maioritariamente - até certa altura, exclusivamente - nas sociedades pré-industriais, definidas exactamente pela ausência de bens de massa. Focando os efeitos desintegradores da entrada dessas sociedades na economia mundial ou, no seu reverso, destacando as capacidades de assimilação dos bens e dinheiro ocidentais pelos sistemas tradicionais de troca, as pesquisas antropológicas estavam orientadas para o extra-ocidental, caracterizado pela ausência do consumo de massa. Verifica-se, portanto, que a negligência do consumo é ela própria resultado dessa opção estruturante da antropologia pelas sociedades pré-industriais. Para lá do possível enquadramento, mais ou menos directo, no que poderia vir a ser uma temática geral do consumo, os estudos antropológicos não conduziam à constituição de uma área de estudo diferenciada porque estavam centrados nas especificidades das sociedades tradicionais. Mas isso só pôde ter como efeito uma tão prolongada falta de interesse pelo consumo porque o contexto académico disciplinar francamente tendia para a produção de concepções polarizadas das sociedades "primitivas" e das sociedades "ocidentais", dando corpo àquilo que J. Carrier (1995a) designa por construção de "ocidentalismos". A noção de ocidentalismo remete para as representações simplistas e essencialistas do Ocidente produzidas pela antropologia, não tanto em virtude de uma intenção positiva de o caracterizar ou analisar, mas mais como contraponto implícito das imagens, igualmente estilizadas, construídas sobre as sociedades extra-ocidentais. A elaboração deste conceito por Carrier é devedora do conceito de orientalismo e respectivo trabalho crítico de E. Saïd (1978); porém, no conceito de ocidentalismo há uma alteração do ponto de focagem que leva a reconhecer, não só a produção de representações simplistas do Oriente, mas também o facto de estas pressuporem - mesmo que só implicitamente - a sua comparação com a sociedade ocidental, daí resultando a produção de representações do Ocidente, também elas, essencializadas. Ou seja, os orientalismos e os ocidentalismos, enquanto imagens simplificadas, são eles próprios intensificados pela dramatização da distância e da diferença relativamente ao seu oposto. O corpo teórico disciplinar tem produzido inúmeras destas imagens simplificadas, ${ }^{1}$ mas, para a questão que aqui nos interessa - a prolongada negligência do consumo -, a mais relevante é o modelo teórico de Marcel Mauss (2001 [1923-1924]) e a sua oposição da sociedade industrial, enquanto sistema de mercadorias, à sociedade pré-industrial, enquanto sistema de dádivas. Como Caplow (1982) argumenta a propósito da importância de Mauss e do seu Ensaio, se devemos reconhecer-lhe o mérito de, logo em 1924, ter estabelecido a troca ritualizada

$1 \quad \mathrm{Na}$ "Introdução" a Occidentalism..., Carrier (1995a) refere especificamente Marx e as suas sociedades capitalista e pré-capitalista, Durkheim e as suas sociedades de solidariedade orgânica e mecânica e Lévi-Strauss e as suas sociedades quente e fria. 
de presentes como campo de pesquisa académica, simultaneamente não podemos também deixar de o responsabilizar pelo retardar do desenvolvimento de uma teoria da troca e questões adjacentes, exactamente pela sua insistência na dádiva como característica exclusiva das sociedades não-ocidentais.

Atentemos no modelo teórico de Mauss, tentando destacar as essencializações dos dois tipos de sociedades por ele produzidas. Sabemos todos que o Ensaio sobre a Dádiva (Mauss 2001 [1923-1924]) se debruça sobre a natureza das trocas e contratos nas, então designadas, sociedades primitivas e arcaicas, e que às transacções sob a forma de dádiva aí realizadas opõe os sistemas de compra e venda ocidentais. Para Mauss, ambos os tipos de sociedade podem possuir mercados e dádivas, mas a sociedade primitiva e a sociedade ocidental distinguem-se inelutavelmente pela natureza do regime de trocas existente em cada uma, dado que, subjacente a ele, estão regras e ideias profundamente diferentes sobre as relações entre as pessoas e as coisas. Este é o ponto crítico: Mauss concebe os sistemas de prestações totais como tendo subjacentes uma moral e um direito que só sob a forma de vestígios se encontram no Ocidente. Em virtude disso, o "mecanismo espiritual" que sustenta o funcionamento daqueles sistemas aparece como não operativo nas nossas sociedades. Só nas sociedades primitivas e arcaicas as transacções não são nunca simples trocas de bens ou riquezas, de coisas meramente úteis (2001: 55), porquanto só aí as coisas não são inertes (2001: 64); só aí apresentar qualquer coisa a alguém é apresentar qualquer coisa de si (2001: 66), porque só aí existe uma mistura de laços espirituais entre as coisas e os indivíduos (2001: 68); só aí o objectivo das trocas é antes de tudo moral, visando-se produzir com o objecto um sentimento amigável entre duas pessoas (2001: 79); só aí a obrigação de dar se exprime de uma forma mítica ou simbólica pela qual a comunhão e a aliança estabelecidas são relativamente indissolúveis (2001: 103); só aí as coisas moral e materialmente preciosas surgem distinguidas dos objectos utilitários comuns (2001: 130), porque só aí os objectos são considerados feéricos e têm uma individualidade própria (2001: 134).

Tudo isto aconteceria assim porque naquelas sociedades os conceitos económicos e jurídicos não aparecem separados nem sob a forma de abstracções e, portanto, o mercado não pode ser um lugar de contrato individual puro. Como, nas sociedades ocidentais, a separação entre pessoas e coisas é a base do próprio sistema de propriedade e poucos serão os itens não alienáveis no mercado, fica pressuposto que aos membros destas sociedades não restam senão relações meramente impessoais e utilitárias com os bens e os objectos. Este ponto é bastante sensível porquanto, de facto, Mauss não discute nunca os sistemas de compra e venda, dedicando exclusiva atenção à dádiva, mas, por oposição implícita, os membros das sociedades ocidentais aparecem arredados da possibilidade de se ligarem singular e/ou simbolicamente às coisas ou de com elas expressarem algo mais que não a sua compra no mercado. Ao definir a natureza 
da dádiva como incompatível com a economia de mercado, Mauss erradica a possibilidade de os membros das sociedades ocidentais poderem estabelecer outras relações com os objectos que não as da impessoal troca comercial, recusando-lhes, portanto, quer a possibilidade de outras formas de "posse" e apropriação dos bens, quer a sua utilização como meio de estabelecimento de relações pessoais entre os sujeitos. ${ }^{2}$

Enquanto ocidentalismo, o modelo teórico que opõe presente e mercadoria é responsável pela criação de um mundo dual, através do qual se concretizam idealizações positivas das sociedades pré-industriais e negativas das sociedades industriais. A distinção entre presente e mercadoria surge, depois, aplicada à identidade social dos objectos e às relações sociais, às formas de transacção e até às próprias sociedades globalmente entendidas. As sociedades de dádiva aparecem como dominadas pelas relações de parentesco e de outros grupos, em função das quais as posições dos indivíduos e as suas relações uns com os outros são definidas. Nas sociedades de mercadoria, os indivíduos aparecem como independentes e autónomos, transaccionando livremente uns com os outros objectos sem ligações particulares com os sujeitos intervenientes. Estas representações, no entanto, não conduzem apenas ao exacerbar e reificar da diferença entre aqueles dois tipos de sociedade. Como todas as imagens essencializadas, o ocidentalismo de Mauss produz também uma simplificação da realidade, que implica o ignorar de vastas áreas da vida nas sociedades ocidentais modernas. ${ }^{3}$ Claro que as sociedades industriais apresentam um elaborado sistema de transacções de mercado, mas, se as simplificamos reduzindo-as a esse sistema, somos levados a esquecer todas as formas de troca e de relações sociais que actuam fora dele. Ou seja, embora as relações e as transacções impessoais de mercadorias sejam importantes na sociedade industrial, reconhecer isso não é o mesmo que aceitar que essas relações são tão essenciais que possamos ignorar todas as outras relações existentes. Reconhecendo que a natureza da sociedade industrial surge distorcida pelo reducionismo do modelo teórico que a define como sistema de mercadorias, percebemos de que modo esse modelo contribuiu para a prolongada negligência do estudo do consumo na antropologia. Não questionando a validade da representação dos sistemas de troca na sociedade industrial como funcionando através de indivíduos autónomos que transaccionam objectos anónimos produzidos em massa, era de todo compreensível a desatenção prestada a esses objectos e às relações das pessoas com eles.

2 Importa clarificar que, ao longo do Ensaio..., Mauss (2001) refere alguns aspectos que matizam, ou até contradizem, uma oposição radical entre os dois tipos de sociedade, mas as representações finais obtidas apresentam o carácter essencialista de descrições absolutas. Por outro lado, o modelo maussiano (Carrier 1995b: 86) é uma estrutura recorrente em muitas fontes antropológicas, sendo que esse difundido dualismo simplifica a própria representação construída por Mauss.

3 Do mesmo modo que o orientalismo correspondente produzirá idênticas simplificações e o ignorar de outros aspectos da vida nas sociedades tradicionais. 
Por outro lado, e ao contrário do que seria previsível dado o novo contexto pós-colonial ter começado já a induzir algumas alterações no sentido do exercício da antropologia at home, a percepção dual dos dois tipos de sociedade e a renovação das respectivas imagens opostas tendem a manter-se - ou até acentuar-se - pelos anos 50 e 60 do século XX, graças à polémica e tensão que rodearam a institucionalização da antropologia económica. A disputa entre formalistas e substantivistas e o subsequente triunfo da corrente substantivista com a afirmação da não-universalidade do modelo da "escolha racional" continuou a orientar a antropologia para o frisar da especificidade das sociedades pré-industriais. M. Sahlins, cuja obra Stone Age Economics (1974 [1972]) é um marco fundamental na medida em que desafia os pressupostos da teoria económica sobre a propensão natural para desejar bens, afirma expressamente na "Introdução" dessa sua obra que com ela pretende instituir uma antropologia económica definida por oposição às interpretações da economia e das sociedades primitivas em termos de economia de mercado. Ou seja, a antropologia esforça-se por rejeitar, não tanto um determinado modelo de análise económica, mas tão-só a sua aplicabilidade às sociedades "primitivas". Desmente-se o desejo universal de bens, mas não se afirma a existência universal de construções sociais de valor sobre os bens. A instituição da antropologia do consumo implicará a superação dessa percepção dual e oposta, meio fundamental para que a disciplina, como defende Miller (1995b), possa expurgar os últimos vestígios de primitivismo ainda latentes e atingir uma nova etapa e a maioridade.

A ultrapassagem da oposição essencialista e simplista entre sociedades pré-industriais e industriais é uma mudança necessária para tornar possível conceber como pertinente o estudo das relações entre pessoas e coisas, independentemente do tipo de sociedade e do regime de produção existentes. Mauss (2001) conseguiu demonstrar como a troca ritualizada de presentes contribuía para a manutenção da solidariedade social nas sociedades pré-industriais; a antropologia do consumo poderá demonstrar como, numa qualquer sociedade, os objectos podem servir para criar e manter relações sociais, proceder à construção activa de formas particulares de cultura, mediar valores fundamentais...

Mas a prolongada negligência do consumo não se ficou a dever apenas ao conjunto de motivos acabado de referir, já que o seu poder explicativo se restringe à disciplina antropológica, quando, de facto, o esquecimento do tópico do consumo abrange também outras áreas disciplinares. D. Miller (1995c), quando passa em revista a literatura produzida nas outras disciplinas sociais e humanas, fica surpreendido com o facto de quase nada ter sido escrito sobre consumo na sociologia, geografia e história. Esta falta de interesse por parte de todas as disciplinas, quando o consumo está presente ou relacionado com a grande maioria das actividades humanas, só pode resultar de percepções académicas ideologicamente constrangidas, cujas abordagens da sociedade e 
sistema capitalistas têm implícito o carácter subsidiário e menor dos fenómenos de consumo, por contraste com a centralidade e importância da produção. Um segundo conjunto de motivos relaciona-se, então, com constrangimentos ideológicos que se fazem sentir graças à forte influência do modelo marxista, cujos efeitos se desdobram quer no centrar da atenção sobre a produção e o trabalho em detrimento do consumo - como comprovado pela correspondente abundância de pesquisas em todas as disciplinas -, quer no conceber necessariamente como um mal a mercadorização da sociedade. ${ }^{4}$

O modo mais eficaz de clarificar a influência marxista é prestar um pouco de atenção ao pensamento e modelo teórico de Karl Marx. É sabido que a produção é uma categoria fundamental em Marx, sendo vista como a chave da existência humana, na sociedade e na história. O que os homens são coincide com o modo como produzem e a história é definida pelo desenvolvimento e sucessão de diferentes modos de produção, sendo a própria luta de classes a materialização das diferenças relativamente à propriedade desigual dos meios de produção. Compreensivelmente, o trabalho produtivo é enfatizado como o lugar por excelência da autocriação e como a verdadeira fonte de valor. A identidade dos indivíduos é criada pelo seu trabalho, através do qual se concretiza a transformação da natureza e a satisfação das necessidades humanas. Para além disso, graças à noção de valor de uso, o produto do trabalho surge como tendo tanto mais valor quanto mais for capaz de servir as genuínas necessidades dos indivíduos, i.e., quanto mais for capaz de ser socialmente útil.

No modo de produção capitalista, a produção ocorre sob condições de estranhamento tão decisivas que o trabalho não permite o desenvolvimento mas, antes, a alienação do sujeito. O trabalhador aliena-se no próprio acto da produção, já que o seu trabalho é despersonalizado e submetido ao ritmo das máquinas e da organização capitalista; mas, para além disso, o trabalhador aliena-se também no próprio produto do seu trabalho, porque o bem produzido serve, não para a satisfação das suas necessidades, mas para o aumento do lucro do capitalista através da mais-valia obtida com a sua venda. Segundo Marx, um qualquer produto possui um valor de uso - correspondente às suas qualidades intrínsecas - e um valor de troca - que é relativo e variável, dependendo das vicissitudes do mercado. Os produtos tornam-se mercadorias quando não são produzidos para consumo do produtor mas para o consumo social através da troca, i.e., quando participam de uma economia de mercado e criam mais-valias ao serem revendidos. A produção, ao criar bens lançados no mercado, cria mercadorias; a mercadorização da sociedade vai muito longe, já que a força do trabalho passa, ela própria, a ser uma mercadoria comprada e vendida

4 Cruzando estes constrangimentos ideológicos com o primeiro conjunto de motivos referido percebe-se como mutuamente se reforçam: a antropologia procurava não só demonstrar, mas também defender da contaminação, as especificidades das sociedades pré-industriais. 
no mercado. Apesar de serem o resultado do trabalho, as mercadorias surgem como que dotadas de uma existência independente; no capitalismo, o mercado surge dotado do poder mágico de produzir valor, mais valor, caindo-se, assim, no fetichismo da mercadoria. O valor da mercadoria deixa de estar dependente do seu valor de uso e, a partir daí, as relações pessoais entre os indivíduos transformam-se em relações entre coisas (Marx 1979 [1867]).

O modelo proposto por Marx e a sua posterior interiorização por parte de marxistas e, até, não marxistas fornecem as bases ideológicas da negligência do estudo do consumo. O seu impacto pode ser evidenciado através de três pontos:

1 Por si só, a ênfase na produção faz com que o consumo apareça desvalorizado e percebido como mero resultado dos interesses capitalistas, que criam necessidades e desejos, aumentando a procura segundo os objectivos da produção. O consumo aparece reduzido à venda de mercadorias e obtenção das respectivas mais-valias;

2 Eleger o trabalho como único local de auto-realização humana e ligar em exclusivo o valor positivo do produto do trabalho ao seu valor de uso conduz à desvalorização de todas as formas de acção humana e relações sociais ocorrendo fora do local de trabalho (excepto, talvez, a arte). Fica justificada a ausência de análise das actividades culturais dos sujeitos e a impossibilidade de vislumbrar o consumo como podendo abarcar relações sociais criativas;

3 Insistir no carácter exterior e oposto das mercadorias produzidas pelo sujeito impede que se conceba os objectos produzidos e distribuídos em massa como cultura material de que importa perceber o uso social e o papel como instrumento de auto-realização do sujeito.

Existe, portanto, uma relação entre a preponderância extensiva do esquema marxista nas ciências sociais e, simultaneamente, a negligência do consumo enquanto foco de pesquisa ou a adopção de abordagens reducionistas sobre ele. Esta tendência, englobando simultaneamente falta de interesse e adopção de pressupostos negativos, repercute-se também no estudo das inter-relações sociais associadas com o consumo e no estudo da cultura material. Reduzir o consumo à expressão dos interesses capitalistas, como o resultado da criação de necessidades e desejos artificialmente suscitados para satisfazer os interesses da produção (Haug 1986; Preteceille e Terrail 1985); adoptar uma postura de crítica geral à "cultura moderna", aceitando o pressuposto da sua inautenticidade ou do seu carácter materialista/fetichista, que reduz as pessoas a coisas e onde os objectos surgem como perturbadores das genuínas relações entre as pessoas, como faz genericamente a crítica pós-moderna; desatender por completo o estudo dos artefactos enquanto formas culturais, 
mas, simultaneamente, aceitar o pressuposto das consequências negativas do crescimento da cultura material; todos estes desenvolvimentos (ou a falta dos seus inversos) são manifestações do mesmo conjunto de condicionalismos intelectuais e ideológicos.

A este nível de análise torna-se claro que os modelos teóricos de Mauss e Marx podem ser vistos como duas versões de um mesmo e único ocidentalismo. Partindo das sociedades de dádiva ou da sociedade capitalista, tanto num como noutro caso a representação construída da sociedade ocidental - ou "sociedade de consumo" - surge sempre como o reverso negativo e criticado de outro tipo de sociedade positiva e nostalgicamente valorizada. ${ }^{5}$ Por isso, uma forma sucinta de propor a ultrapassagem dos condicionalismos teórico-ideológicos apontados e respectivas imagens simplistas e redutoras é defender o fim da colagem entre consumo e capitalismo ou, mais especificamente, entre crítica ao consumo e crítica ao capitalismo. Só deixando de insistir no carácter problemático, oposto e antagónico das relações entre sociedade e mercadoria se pode estar disponível para conceber a mercadorização da sociedade, não como a encarnação de todo o mal, mas como uma tendência dominante da sociedade actual cujas múltiplas facetas urge descobrir e perceber. As críticas às desigualdades e à opressão associadas ao sistema capitalista não devem impossibilitar o estudo aprofundado da nossa cultura industrial.

\section{O INTERESSE PELO CONSUMO}

Depois de compreender os motivos, mais e menos circunscritos à disciplina, da tardia emergência da antropologia do consumo, seguir as etapas do seu desenvolvimento é seguir os esforços que foram sendo concretizados para a superação dos condicionalismos existentes. Nas páginas seguintes, dou conta dos contributos de um conjunto alargado de autores e obras que constituem uma selecção das referências mais significativas. Importa ter em mente que a mudança no sentido da constituição do consumo como objecto de estudo não é apenas um simples acrescento ao repertório da antropologia; é um acontecimento que, traduzindo a superação daquela percepção dual entre dois tipos de sociedade e, portanto, dos últimos vestígios de primitivismo, constitui uma transformação da natureza da disciplina como um todo.

\subsection{Os anos 70 e a emergência da antropologia do consumo}

Antes dos anos 70, apenas o trabalho pioneiro de T. Veblen (1970 [1898]), The Theory of the Leisure Class, surge como uma referência incontornável. Contudo,

5 Como curiosidade, refira-se que, num outro contexto de análise, Carrier coloca a questão da seguinte forma: “a atmosfera intelectual de Paris na primeira metade do século XX estava impregnada com as ideias marxistas e Mauss obviamente absorve-as” (1995c: VII). 
produzida numa época que realizava a transição para o consumo de massa e adoptando um enquadramento evolucionista, a sua teoria do consumo ostentatório é fortemente datada e focalizada num segmento muito particular da população dos Estados Unidos, a classe ociosa. Entendida como a classe cujos membros tinham a capacidade de se manterem sem trabalhar, a classe ociosa era composta por um grupo particular de pessoas ricas para as quais a riqueza per se era menos importante do que a riqueza exibida como distanciamento relativamente ao mundo das necessidades práticas. Tal comportamento seria adoptado não pela aristocracia tradicional, que nunca tinha estado envolvida com o trabalho e tinha herdado a sua situação, mas pelos nouveaux riches cuja acumulação de riqueza tinha implicado um envolvimento muito mais directo com o processo de trabalho. As estratégias adoptadas pela classe ociosa para criar um distanciamento entre si e o mundo do trabalho e emular a aristocracia eram a ausência de trabalho e a posse de riqueza, ambas exibidas de forma muito exagerada, a que Veblen (1970) chamou "lazer ostentatório" e "consumo ostentatório". Embora esta classe expressasse o seu status de modos muito diversos, traduzido, por exemplo, na posse cuidada de animais de estimação ou em contratar criados que ostensivamente não tinham nada para fazer, ou tinham muito pouco, para Veblen (1970: 86) a riqueza e o status aparecem linearmente unidos, sendo frisada a ligação entre a "força pecuniária" e o elevado status dos indivíduos. Deste modo, consumo e lazer ostentatórios surgem como meios de exibição das distinções sociais e os objectos são claramente entendidos como marcadores de status. Por oposição com as sociedades de pequena dimensão, nas sociedades de massa, tidas como caracterizadas pela emulação e competição de status, o julgamento da reputação das pessoas surge vinculado aos objectos exibidos.

Cumprida a menção a Veblen, é possível apontar com relativa precisão o fim dos anos 70 do século XX como a data de emergência da antropologia do consumo. Na literatura imediatamente anterior, o consumo não é concebido como merecedor de atenção, não sendo adoptada uma perspectiva que vise abordar o seu papel no mundo contemporâneo. A produção antropológica, nomeadamente a ligada à corrente substantivista da antropologia económica, desafiava pressupostos como os da escolha racional ou da maximização do lucro, mas continuava a situar os debates ao nível da especificidade das sociedades pré-industriais, i.e., pré-capitalistas. Tomando o trabalho de Sahlins (1974), Stone Age Economics, como um apreciável exemplo desse tipo de abordagem substantivista, percebe-se a sua irrelevância para a emergência da antropologia do consumo, porquanto, ao mesmo tempo que demonstra que a troca pode ser um fim em si mesma e que "os fluxos de bens caucionam ou instauram as relações sociais" (1974: 238), limita a reivindicação desses objectivos sociológicos da troca ao âmbito da "economia primitiva". É verdade que Sahlins fala sempre da troca primitiva como um continuum de formas englobando também 
a pura troca comercial, mas o esbatimento da velha oposição entre mercadoria e dádiva não acontece, dado que se mantém vigorosa a percepção polarizada das realidades socioculturais nas sociedades industriais e pré-industriais.

A possibilidade de se constituir um subcampo disciplinar que mereça o título de antropologia do consumo surge, então, apenas quando os investigadores são capazes de adoptar uma nova perspectiva, em que o interesse pelos bens e serviços consumidos e suas modalidades de consumo se sobrepõe à atenção ao modo como são produzidos; i.e., quando, independentemente de serem ou não bens de consumo de massa, se coloca a questão de perceber e elucidar as construções sociais de valor subjacentes ao seu consumo. Os pioneiros desta nova perspectiva foram M. Douglas e B. Isherwood (1978) e P. Bourdieu (1979). Curiosamente, revendo posições anteriores e passando a considerar merecedores de atenção os bens produzidos em massa, também M. Sahlins (1976) aqui deve ser referenciado.

No livro Culture and Practical Reason, Sahlins (1976) discute as propriedades culturais dos bens de consumo da sociedade norte-americana, examinando os bens alimentares e o vestuário enquanto sistemas. Cada sistema de bens é visto como constituindo um "código de objectos" que, remetendo para uma ordem cognitiva complexa de categorias culturais e de relações entre elas, transmite distinções e categorias culturais que podem ser manipuladas pela própria manipulação dos bens. Segundo Sahlins, terá sido o significado cultural sedimentado nos bens que permitiu à sociedade ocidental transformar "a contradição básica da sua construção num milagre de existência, uma sociedade coesa de perfeitos estranhos" (1976: 203).

Na obra The World of Goods, Douglas e Isherwood (1978) operam uma viragem idêntica, contrapondo ao ponto de vista dos economistas sobre as fontes de desejo dos bens a perspectiva alternativa de os ver como sistemas de categorias, analisando-os na sua função expressiva e simbólica. O significado dos bens excede o seu carácter utilitário e o seu valor comercial e de exibição de status. Grande parte do seu significado assenta na capacidade de transportarem e comunicarem significado cultural. Os bens ajudam na criação de uma ordem cognitiva que, baseando-se em pressupostos e crenças culturais, alcança a estabilização das suas categorias através da materialidade dos objectos, i.e., operando simultaneamente nos mundos material e cognitivo, os objectos ajudam a tornar "visíveis e estáveis as categorias da cultura" (1978: 59). As ideias da cultura, que pela sua natureza são intangíveis, alcançam uma certa "concretitude" através dos objectos, que são uma parte visível da cultura.

Se as duas obras referidas apresentam traços de confluência evidentes, nomeadamente a crítica ao pressuposto da utilidade e a insistência na ordem cognitiva formada com o auxílio dos bens de consumo, o trabalho de P. Bourdieu (1979), La distinction, apresenta carácter muito diverso. Recorrendo a amplo material empírico, o autor traça uma tese complexa que frisa a centralidade das 
práticas de consumo e manifestações do gosto na criação e manutenção das relações sociais de dominação e submissão. A estrutura de consumo é tida como a chave para a reprodução das relações de classe e os objectos como jogando um papel fundamental na naturalização da ideologia. Bourdieu começa por fazer com que o gosto estético deixe de ser entendido como "preferência natural" e passe a ser olhado como uma das disposições do habitus. Recorre ao conceito de estética de Kant - a contemplação distanciada que transcende a imediatez da experiência - e demonstra que esta é apenas a noção estética adoptada pela classe social dominante. A estética da cultura popular é antikantiana, traduzida na preferência pelo entretenimento imediato, pelo prazer como reacção instintiva e sensual. A distinção entre estéticas kantiana e antikantiana é derivada das condições materiais da existência, mas, simultaneamente, fornece um esquema classificatório aplicado em múltiplos domínios. Na classe trabalhadora, a imediatez dos gostos deriva da experiência do trabalho manual e da pressão por não estar garantido o acesso ao básico em termos de subsistência e conforto, o que origina o respeito e o desejo do imediato, do físico, do sensual. Outros indivíduos, que tenham crescido experienciando abstracções como o capital ou a educação formal e cujas necessidades básicas estejam garantidas, tendem a cultivar um distanciamento relativamente a essas necessidades e desenvolvem um gosto assente no respeito e desejo do abstracto, do distanciamento, do formal. As diferentes condições objectivas da existência são interiorizadas através do habitus, expressando-se em gostos diferentes. ${ }^{6}$ Partindo daqui, Bourdieu mapeia as diferenças de gosto como forma de aceder às diferenças entre os grupos sociais; o padrão de bens consumidos e a constituição da ordem social aparecem estreitamente relacionados. O gosto desdobra-se em múltiplos domínios do consumo de massa, onde toda a manifestação de uma diferença pode ser olhada como um marcador social que tem subjacentes certas condições de existência. Enquanto expressão de pertença a um determinado grupo social, os gostos funcionam como traços de união e como factores de exclusão: unem num mesmo estilo de vida os agentes que partilham as mesmas condições objectivas de existência, distinguindo-os de todos os outros.

Apesar de nenhuma das três obras referidas chegar a fornecer uma teoria do consumo ou da cultura material e de as mesmas apresentarem diversas limitações, todas elas marcam uma viragem no sentido de uma antropologia do consumo porque concretizam novas perspectivas de abordagem dos bens de massa. Em Sahlins (1976) e Douglas e Isherwood (1978), as questões ideológicas são

6 Na tese de Bourdieu, a naturalização da ideologia concretiza-se também através da utilização do nível educacional e correlativa eleição da meritocracia como princípio legitimador da hierarquia social. A educação, supostamente, gera distinções sociais baseadas no mérito mais do que no nascimento ou na riqueza, mas, procedendo a análises que cruzam ocupação e nível educacional, o autor conclui que a educação de massas se traduziu num declínio da mobilidade social, tendo resultado apenas na inflação das qualificações dos empregados. 
em grande parte ignoradas, mas não restam dúvidas de que as novas propriedades atribuídas aos bens de consumo foram fundamentais para que a autenticidade dos objectos deixasse de surgir ligada à sua origem não industrial e a mercadorização da sociedade pudesse ser encarada segundo ângulos que não apenas o dos interesses capitalistas. Na tese de Bourdieu também se podem referir várias limitações: as estruturas de consumo são encaradas em exclusivo como formas objectivadas de reprodução dos interesses de classe, permanecendo desatendidas quaisquer outras dinâmicas sociais de consumo. Mas é inegável que esta tese concede aos bens de consumo um papel bem mais essencial do que as anteriores concepções. As particularidades dos objectos são vistas como podendo ajudar a gerar as objectivações pelas quais as pessoas procuram distinguir-se. Não se trata de os bens de consumo meramente reflectirem distinções, mas de serem um instrumento para essas distinções. Concebendo o habitus como estando profundamente enraizado, tanto nas divisões sociais e esquemas cognitivos como na cultura material, Bourdieu consegue uma via explicativa sobre como os consumidores são capazes de seleccionar os bens apropriados para si e para os seus no meio da extraordinária panóplia disponível. No seu conjunto, estas novas abordagens traduzem a emergência de uma concepção inovadora que, ao reconhecer a possibilidade de ligações específicas e simbólicas entre pessoas e coisas independentemente da forma de produção e circulação destas últimas, sanciona a pertinência do seu estudo também nas sociedades industriais.

\subsection{Os anos 80 e a consolidação da antropologia do consumo}

Depois dos primeiros anos da década de 80, vários são os investigadores cujos trabalhos demonstram outros tantos modos de contextualização do consumo pela antropologia e respectiva consolidação desta subárea disciplinar. Convém, aliás, ter presente que, por esta altura, o consumo se torna um subcampo académico em várias outras disciplinas, tornando evidente a transversalidade da temática e a multiplicidade de objectos de estudo com ela relacionados. ${ }^{7}$ Mas a passagem de uma ausência total de interesse para o seu inverso não se traduziu, como não seria de esperar, no desaparecimento automático dos anteriores condicionalismos ideológicos e, portanto, muita da literatura inicialmente produzida surge repleta de propostas moralizantes. Apesar de o estudo do consumo ganhar a sua própria autonomia e se libertar da produção, o influente modelo marxista continuou a fazer-se sentir, sendo possível detectá-lo subjacente a muita da literatura produzida. A "sociedade de consumo" é presumida, não apenas como tendo uma economia estruturada à volta da venda e promoção de bens - mais do que da sua produção -, mas também como 
sendo uma sociedade em que as pessoas se deslumbram alienadamente com os sempre mais altos níveis de consumo ambicionados. A "cultura de massas" é entendida, basicamente, como a cultura daqueles consumidores alienados, tida como uma cultura individualista e fragmentada, envolta em valores materialistas e desumanizantes. ${ }^{8}$

Em paralelo com essas concepções negativas da contemporaneidade, um ponto de partida frequente para o estudo do consumo é percepcioná-lo como erosão cultural, vendo como uma e a mesma coisa a mercadorização e a "homogeneização descaracterizadora" da Modernidade. O crescimento vertiginoso da cultura material na sua forma massificada de produção e distribuição - cuja natureza social correspondente não foi sendo estudada concomitantemente é tendencialmente associado a atitudes "materialistas" ou "fetichistas" que se desenvolveriam porque as pessoas, em vez de participarem em genuínas interacções sociais, se focalizariam mais nas relações com os objectos per se. As sociedades recentemente inseridas na economia mundo são tidas - e lamentadas - como tendo hipotecado as suas especificidades culturais a troco de uma pseudomodernização que mais não é do que massificação e perda cultural. ${ }^{9}$ Tais temores têm subjacente a crença de que os membros das sociedades pré-industriais desenvolveriam relações mais naturais e autênticas com os objectos e com a sua cultura, o que em si mesmo implica fazer depender do processo de produção a autenticidade e manutenção cultural.

Outra possibilidade de partida para o estudo do consumo tem sido deslocar o ponto de focagem para o tema da resistência às forças hegemónicas da mercadorização, o que, apesar de tudo, pode ser entendido como um certo movimento reactivo à tendência mais crítica da "cultura de massas", já que fica implícito um papel mais activo dos sujeitos, individual e colectivamente. A propósito de sociedades de pequena escala recentemente sujeitas ao mercado ou analisando fenómenos do chamado "consumo verde", os investigadores procuram identificar e caracterizar linhas de resistência e conteúdos de protesto, fazendo intervir uma componente política no significado do consumo. A teorização dos "prazeres do consumo" de Certeau (1984) pode ser considerada o exemplo extremo dessa abordagem do consumo enquanto táctica de subversão.

É possível, porém, referir também alguns trabalhos que vencem estas tendências e contribuem definitivamente para um estudo autonomizado e mais frutuoso - do consumo. Um que merece destaque é o livro editado

8 Para os pós-modernos, a "sociedade pós-moderna" é identificada como a "sociedade de consumo"; para além das variantes entre autores, o que os une é a ideia da fragmentação da cultura e crescente importância do símbolo relativamente à substância na vida quotidiana.

9 Trabalhos como os de Hart (1982) e Taussig (1980) são bons exemplos da manutenção da noção marxista de mercadoria e da mercadorização como pressupondo, não apenas o aumento geral da abstracção no trabalho, mas também a destruição das relações habitualmente envolvidas noutras esferas sociais. 
por A. Appadurai (1986), The Social Life of Things. Para além de reunir um interessante conjunto de estudos de caso ilustrativos de subtis e múltiplos manuseamentos sociais realizados sobre objectos diversos, na "Introdução" Appadurai discute a questão da oposição entre presente e mercadoria. Adoptando uma posição crítica severa relativamente à literatura tradicional, demonstra a necessidade de abandonar aquela dicotomia entre presente e mercadoria, já que é graças a ela que as análises se permitem descartar os bens de massa, vendo-os como produtos dessocializados.

Outra obra a vários títulos inovadora e significativa para a consolidação da antropologia do consumo é o trabalho de D. Miller (1987), Material Culture and Mass Consumption. Em primeiro lugar, porque, de facto, fornece uma teoria geral do consumo, reconhecendo-o como uma categoria chave da Modernidade. Depois, porque parte do mesmo esquema filosófico de Hegel que Marx havia utilizado, mas invertendo-lhe a respectiva leitura em vários pontos e contextualizando o consumo em termos de objectificação da cultura. Finalmente, porque com essa tese contradiz as perspectivas niilistas e trágicas habituais e enfatiza o papel potencialmente activo dos consumidores na ressocialização de mercadorias. Assumindo a "seriedade" da cultura de massas, Miller propõe-se atingir uma melhor compreensão do lugar dos bens na contemporaneidade. De Hegel retém o esquema do processo de desenvolvimento do sujeito como sucessão de externalizações e reincorporações, através da qual é resolvida a dicotomia sujeito-objecto e atingida uma consciência cada vez mais complexa desse sujeito (Duarte 2002). Partindo daqui, Miller constrói o seu conceito de "objectificação", entendido como o processo dinâmico pelo qual uma dada sociedade se desenvolve através da sua projecção num mundo externo e subsequente reincorporação dessa mesma projecção. Esta pode recobrir diversas formas externas, incluindo as grandes instituições e ideias como a nação ou a religião, a cultura material ou os sonhos individuais. Os bens de massa, na sua panóplia diversificada de itens, constituem uma forma particular de externalização da sociedade industrial. Importa que o processo de objectificação não fique pela metade, i.e., que o mundo de objectos criados pela sociedade não se transforme em algo abstracto e separado dela, mas que, pelo contrário, a sociedade consiga reapropriar-se da cultura que produziu. O consumo de massa é o meio pelo qual a sociedade industrial pode realizar essa reapropriação da cultura material, que é uma parte significativa da sua cultura.

$\mathrm{Na}$ teoria proposta por Miller, juntamente com o processo de objectificação, é central a ideia de que a sociedade moderna tem uma natureza intrinsecamente contraditória, sendo possível identificar três dilemas modernos: a produção industrial, o Estado moderno e o modernismo cultural. Para efeito da presente análise, a mais relevante é a primeira dessas contradições. $\mathrm{Na}$ indústria, a contradição consiste em esta ter criado numerosos produtos que as pessoas apreciam e desejam e que lhes fornecem benefícios, mas, em simultâneo, 
as instituições produtivas e distributivas contemporâneas terem uma escala tal que só podem ser consideradas abstractas e com tendência para a autonomia, emergindo os seus interesses como opostos aos da massa da população. A noção de objectificação como processo de desenvolvimento e o assumir da natureza contraditória da Modernidade permitem a Miller (1987) evitar o niilismo dominante e escapar à tentação de propor um fim utópico para a história, orientando, pelo contrário, a sua análise para o exame dos modos de experienciação dessa contradição inevitável. Temos uma sociedade industrial que produz e distribui grande quantidade e variedade de produtos através de instituições de larga escala. A cultura material assim criada é uma das projecções externas dessa sociedade; trata-se de alcançar a reincorporação, na própria sociedade, dessa externalização. O mecanismo pelo qual a sociedade realiza a reapropriação positiva da sua forma externa, i.e., assimila a sua própria cultura e a usa para se desenvolver como sujeito societal, é o processo de consumo moderno. Este é um meio pelo qual bens e serviços são retirados das instituições abstractas e distanciadas que os originam e são refundidos como cultura material inalienável. Miller pode atribuir tal tarefa ao consumo porque não reduz os bens materiais comprados ou atribuídos a meras mercadorias facilmente substituíveis por outras. Os bens são, de facto, mercadorias, mas só até ao momento em que são obtidos; até aí, as pessoas confrontam-se com eles através de abstracções como o dinheiro (ou o Estado), por intermédio das quais os obtêm; depois da compra (ou atribuição), a situação muda radicalmente, já que, através desse acto, a vasta panóplia de mercadorias é substituída pela especificidade de um bem particular. A sua especificidade constitui-se por oposição a outros bens e está relacionada com a pessoa do comprador e/ou utilizador esperado. O acto de compra de um bem específico é o começo de um longo e complexo processo pelo qual o consumidor trabalha sobre o objecto comprado e o recontextualiza até, muitas vezes, não mais ser reconhecido como tendo qualquer relação com o mundo de onde veio - o da produção industrial e do comércio de mercadorias -, podendo mesmo tornar-se a negação dessas abstracções quando se transforma em qualquer coisa que não pode ser comprada nem dada. O consumo pode, então, ser definido como o trabalho de recontextualização que translada um objecto da sua condição alienável para uma outra inalienável, e isso deve ser visto como um trabalho de construção cultural.

Esta abordagem de Miller proclama o que até à data parecia difícil de assumir: os bens de massa são a nossa cultura. E são-no, não só porque fazem parte do meio ambiente em que operamos, mas também porque são uma parte integrante do processo de objectificação pelo qual nos criamos a nós próprios como sociedade industrial. A autenticidade dos artefactos como cultura não deriva da sua relação com algum estilo histórico ou processo de manufacturação específico, i.e., não há qualquer verdade ou falsidade imanente neles; há antes a sua participação activa num processo de autocriação social, pelo qual 
se tornam directamente constitutivos do entendimento de nós próprios e dos outros. Num artigo publicado na Man, Miller (1988) concretiza o primeiro exercício de aplicação da sua teoria do consumo. Escolhendo um conjunto habitacional de casas sociais do Norte de Londres como objecto de estudo, procura perceber os modos de apropriação pelos quais os residentes transformam as suas casas/mercadorias - i.e., casas atribuídas por uma instituição pública - em lares privados singularmente apropriados. O foco de atenção recai sobre as modificações concretizadas nas cozinhas. Miller conclui pela ausência de ligação óbvia entre o rendimento familiar e as modificações concretizadas, mas pela clara associação entre estas e o sentido de alienação e estranheza das pessoas relativamente à casa concedida pelo Estado. Os que mais introduzem transformações são aqueles que mais se sentem incomodados com o facto de viverem numa casa social, mas nem todos vêem as casas como estranhas e aqueles que têm uma vida social mais significativa e diversificada realizam menores esforços para modificar a respectiva cozinha. As modificações podem, então, ser entendidas como tentativas para transformar o que alguns sentem como "casas sociais", impessoais e inapropriadas, em algo que passe a abranger a sua identidade pessoal e social.

Outro contributo para a consolidação da antropologia do consumo é o de G. McCracken (1988) na obra Culture and Consumption, onde elucida as vias de interpenetração da cultura e do consumo e sustenta uma teoria alternativa à da semiologia para a análise das propriedades culturais e simbólicas dos bens de consumo. Para McCracken, a grande transformação do Ocidente que assinala a génese da Modernidade inclui uma revolução industrial e uma revolução de consumo e é marcada por um relacionamento, antes inexistente, de dependência mútua entre cultura e consumo. ${ }^{10}$ No mundo ocidental, o consumo é moldado, conduzido e constrangido a todos os níveis por considerações culturais, e a cultura - as ideias e actividades pelas quais os sujeitos constituem e elaboram os seus mundos - tem no consumo um dos meios fundamentais para a sua expressão e difusão, surgindo os bens de massa como instrumentos de reprodução, representação e manipulação das suas categorias e princípios. A extraordinária experiência da constante mudança social característica da nossa sociedade é sustentada, em parte, pelo uso que fazemos dos bens de consumo, que funcionam, simultaneamente, como instrumentos de continuidade e de mudança. Os objectos de consumo são uma espécie de lastro, trabalham contra a deriva cultural porque tornam materiais e ubíquos os princípios e categorias culturais, ${ }^{11}$ e, simultaneamente, são canais de expressão capazes

10 A falta de consenso dos historiadores quanto à data de emergência do consumo moderno (ou revolução do consumo) - Mukerji (1983): séc. XVI; McKendrick, Brewer e Plumb (1983): séc. XVIII; Williams (1982): séc. XIX - é ultrapassada por McCracken (1988) vendo cada uma daquelas datas como momentos-chave da história do consumo e da emergência da Modernidade.

11 Neste ponto, é evidente a proximidade entre McCracken (1988) e Sahlins (1976). 
de se expandirem para integrar novas e inovadoras definições do mundo e dos indivíduos. O objectivo último de McCracken (1988) é demonstrar a extraordinária contribuição dos processos e práticas de consumo para a estrutura e funcionamento da nossa sociedade. Como prática cultural, o consumo não mais pode ser negligenciado. Por outro lado, o reconhecimento das capacidades expressivas da cultura material não deve reduzir-se à comunicação de status. Até ao século XVIII, esse foi o principal significado comunicado pelos bens, mas, com a emergência do consumo de massa, esse é apenas um, e dos mais óbvios, tipos de significados contidos nos bens. McCracken aborda o significado da cultura material como constantemente fluindo de e para diversos locais do mundo social, com o concurso dos esforços colectivos e individuais de designers, produtores, publicitários e consumidores. A análise das relações entre cultura e consumo deve atender a esta qualidade móvel do significado dos bens de consumo. Ao fazê-lo, o novo modelo teórico ultrapassa insuficiências anteriores, pois que reconhecer que "o significado está constantemente em trânsito" (1988: 71) é salvaguardar o carácter dinâmico daquelas relações e também a intervenção activa de vários agentes sociais, entre os quais os consumidores.

Segundo McCracken, para lá de todas as variações possíveis, o trajecto habitual de deslocação de significado dos bens comporta três localizações e dois movimentos de transferência de significado. A localização original do significado radica nas categorias e princípios que regem o mundo culturalmente constituído e que formam, respectivamente, o sistema de distinções básicas e as ideias orientadoras do pensamento e da acção no mundo dos fenómenos e dos sentimentos. Apesar da importância das categorias e princípios culturais e da sua constante construção renovada -, eles não têm presença substancial no mundo que organizam. Um dos meios pelos quais são substancializados é através dos objectos materiais da respectiva cultura, que se tornam o registo visível e vital do significado cultural, de outro modo intangível. Os objectos têm, então, uma função performativa, dando ao significado cultural uma materialidade que, de outro modo, não teria. Esta primeira transferência de significado, do mundo culturalmente constituído para os objectos, encontra na publicidade e na moda os instrumentos fundamentais. O criativo publicitário ou de moda procura unir e tornar similares um bem de consumo e uma determinada representação cultural. O significado cultural localizado nos bens de consumo sofre, depois, uma segunda transferência, agora para os consumidores, através de acções simbólicas ou rituais. Estes são uma oportunidade para os consumidores afirmarem, evocarem, subscreverem ou reverem os sentidos simbólicos convencionais, constituindo-se uma ferramenta poderosa e versátil para a manipulação do significado cultural. McCracken identifica quatro tipos de rituais utilizados para transmitir significado dos bens para os consumidores: de troca, posse, apresentação e despojamento. No ritual de troca, em que um consumidor escolhe, compra e oferece bens de consumo a outra pessoa, o movimento 
de bens é potencialmente também um movimento das suas propriedades significativas; no ritual de posse o consumidor concretiza uma "personalização do objecto", assenhoreando-se de certas das suas propriedades simbólicas, que passam a residir no próprio consumidor; no ritual de apresentação a que o consumidor recorre, por exemplo, quando se arranja para "sair à noite", procura-se capturar propriedades especialmente glamorosas dos bens de consumo, refrescando periodicamente a imagem do consumidor; no ritual de despojamento o actual dono do bem procura erodir as propriedades simbólicas associadas ao seu anterior dono, ou a si próprio se a posse do objecto vai passar para terceiros. De qualquer modo, chegado aos consumidores individuais, o significado cultural residente nos objectos pode ser utilizado com grande liberdade em processos de autodefinição pela apropriação de características significativas elegíveis e manipuláveis. Talvez se deva reconhecer que esta nova percepção dos consumidores como constantemente implicados em tarefas de apropriação e deslocação de propriedades simbólicas não é um contributo desprezível.

\subsection{Os anos 90 e a maturidade da antropologia do consumo}

A partir da última década do século XX, a antropologia do consumo alcança um novo patamar, sendo perceptível um movimento geral de ultrapassagem das tendências moralizantes anteriores e um desenvolvimento do estudo da mercadorização e bens de massa implicando a revisão de muitos dos tópicos anteriores. De incidência mais alargada ou mais circunscritos à disciplina, vários foram os factores que contribuíram para a nova etapa. Entre eles não é irrelevante o trabalho realizado por investigadores genericamente interessados no consumo ocidental que fazem a sua história - das "arcadas" e "grandes armazéns" parisienses (M. Miller 1981; Williams 1982; Chaney 1983; Geist 1983; Laermans 1993; Lancaster 1994) aos malls americanos (Benson 1986) e acabam invariavelmente por interligar essa história com a história da própria Modernidade. Tais estudos têm vindo a fornecer evidência histórica quer da ligação entre consumo e Modernidade - o que reforça os modelos de Miller e McCracken já referidos -, quer do recuo dessa ligação até ao século XVI (Mukerji 1983), localizando temporalmente muito longe a emergência do "consumo moderno" e suas práticas no Ocidente, o que permite inverter a ordem dos efeitos: a "cultura consumista" antecedeu a emergência do capitalismo e ajudou à sua criação. No geral, estas abordagens têm demonstrado que muitas das práticas de consumo tidas como aparentemente recentes têm, afinal, profundos traços no tempo. ${ }^{12}$

12 É possível referir estudos muito recentes em áreas das ciências sociais, como a ciência política (Trentmann 2006) ou a sociologia (Sassatelli 2007), que têm interrogado os processos de construção social do consumo e do consumidor na sua historicidade. Em particular, Sassatelli dedica a primeira das três secções do seu livro à análise histórica do consumo e da emergência da noção de "sociedade de consumo", aí defendendo com vigor que o capitalismo não criou consumidores, tendo [continua] 
Por outro lado, é constatável a proliferação de exercícios de consumo cada vez mais diversificados, desde vários festivais, parques temáticos ou centros comerciais de terceira geração, passando pelas compras por catálogo ou pela Internet, até ao turismo de massa, ao mesmo tempo que se torna igualmente evidente a crescente expansão do consumo no mundo. Em relação a essa expansão e subjacente dependência crescente de mercadorias produzidas por terceiros, surge cada vez mais perceptível que tal dependência ocorre em vários sentidos, atingindo quer os países subdesenvolvidos quer os desenvolvidos. Geralmente associada a académicos trabalhando sob perspectivas da economia política ou do sistema-mundo, a análise de commodity chains tem contribuído indirectamente também para a discussão ou redefinição do que é uma mercadoria. Desde o estudo inaugural de Sidney Mintz (1985), Sweetness and Power: the Place of Sugar in Modern History, onde são fornecidos impressivos detalhes sobre as relações entre o crescimento das plantações de açúcar nas Caraíbas e o crescente consumo de açúcar pela classe trabalhadora na Europa, o traçar da circulação de várias mercadorias globais como o açúcar, o café, alguns frutos ou cereais tem produzido uma significativa literatura reveladora de conexões antes invisíveis, ou desatendidas, entre produção e regimes de consumo separadas por grandes distâncias geográficas, culturais e políticas. A história cultural de cada um desses produtos (e não só a sua consideração em termos económicos ou nutricionais) faz sobressair de forma poderosa o cruzamento da produção com o consumo e seus efeitos, mormente políticos, aos níveis local e global.

Todo este contexto torna impossível a manutenção dos "ocidentalismos" habituais e da percepção do consumo em termos subsidiários relativamente à produção capitalista. Torna-se uma constatação geral que as pessoas, ao realizarem actos de consumo, se envolvem nessas actividades enquanto aspectos centrais das suas vidas e que o estudo do consumo deve considerar as múltiplas relações sociais envolvidas naqueles actos. Pode dizer-se que é adoptada uma abordagem mais fenomenológica e menos ideologicamente determinada do consumo e suas práticas, e que este passa a ser olhado como actividade prática, moral e contextual que serve de meio de expressão, nem sempre autoconsciente, de vários valores e construções sociais.

De forma mais específica para a antropologia do consumo, o novo contexto académico e analítico vai conduzir quer ao desenvolvimento de algumas das anteriores linhas de pesquisa, quer à revisão de outras. Talvez se deva começar por assinalar como a antropologia do consumo foi central no documentar de respostas diversas às possibilidades da mercadorização, demonstrando grandes diferenças regionais. Ultrapassada a focagem da expansão do consumo como 
reverso do falhanço primitivo da resistência à "ocidentalização capitalista" e concretizadas pesquisas etnográficas efectivas sobre fenómenos de consumo em diferentes zonas do globo, investigações focando, por exemplo, o uso de computadores em África (Jules-Rosette 1990), a moda no Senegal (Heath 1992) ou no Japão (Tobin 1992), o consumo de alta-costura em Singapura (Chua 1992), de telenovelas e Coca-Cola em Trindade (Miller 1992 e 1997) ou da cultura material nos Camarões (Rowlands 1995), são investigações que conduzem à detecção e análise de diversos regimes de consumo. Portanto, um ponto essencial do desenvolvimento mais recente da antropologia do consumo é a relativização das próprias práticas de consumo.

O movimento no sentido da consideração de modos particulares de consumo é, entretanto, reforçado pelo desenvolvimento de estudos antropológicos sobre a globalização e as relações entre o local e o global. A diversidade de regimes de consumo entre regiões e sociedades torna mais evidente o carácter simplista da assunção da mercadorização como sinónimo de erosão cultural, e os estudos da globalização tocando o consumo fazem-no surgir como potencial gerador de novas formas culturais que contradizem a homogeneização cultural do mundo. Pesquisas sobre fluxos globais evidenciam que as redes que conectam o mundo são cada vez mais densas, nomeadamente pela circulação contínua de mercadorias cujas modalidades de consumo emergem como estratégias diferenciadas de estabelecimento e manutenção das identidades étnica, social e individual. O consumo surge, então, como categoria-chave da Modernidade também porque através dele são accionadas estratégias de afirmação de identidade (Friedman 1990). Tudo isto consolida o reconhecimento de que, como o desejo por bens não é natural, também per se os bens de massa não podem ser nem negativos nem positivos. Compreender o impacte do consumo implica atender aos fundamentos sociais e pessoais da procura, dando conta das variações nos modos de posse e uso dos bens, o que reforça a tendência de pesquisas documentando a diversidade de regimes de consumo entre géneros, classes e regiões, assim como as relações entre o consumo e a construção de subjectividades. Nestas pesquisas, o nível de problematização tende a ultrapassar a ligação linear entre bens e sujeitos, evitando uma assimilação estrita entre categorias de consumidores e categorias sociais de classe e status (Miller et al. 1998). Em suma, o significado dos bens de consumo é percebido como performativo, variando de acordo com as situações, os tempos e os espaços, pelo que é pertinente atender ao seu papel na produção de identidades e na expressão de valores. A esfera do consumo é crescentemente entendida como um mundo pragmático, no qual podem observar-se múltiplos processos humanos de criação de valor. Tais desenvolvimentos são de extrema importância, porquanto dar conta dos fundamentos sociais e pessoais da procura e reconhecer modelos mais locais e particulares de uso das mercadorias são passos fundamentais para sustentar quer o abandono da tendência redutora do consumo como sinónimo 
de erosão cultural, quer a ultrapassagem do pressuposto da superficialidade da cultura mercadorizada. Porque o conceito de cultura não pode ser confundido com um qualquer conjunto de objectos, nem a sua autenticidade vista como ameaçada pela chegada dos bens de massa, a demonstração de respostas diversas às possibilidades de consumo é um contributo fundamental do desenvolvimento da antropologia do consumo.

Os anos 90 concretizaram, portanto, a ultrapassagem da anterior linha de pesquisa centrada na resistência, substituindo-a pela problemática da apropriação. A temática da resistência, sobretudo na sua forma extrema de identificação com a rejeição dos bens de massa, é radicalmente posta em causa por trabalhos como o de Abu-Lughod (1990), dedicado ao uso de lingerie entre as mulheres beduínas, ou a discussão de Hugh-Jones (1992), relativa à recusa do materialismo dos índios amazónicos tida como garantida pelo Ocidente. A experiência de Hugh-Jones na região fornece-lhe observações muito contrastantes com aquela ideia, dado ter constatado uma "ganância avarenta" de bens. Em função desse contraste, discute o problema de os debates no Ocidente constantemente usarem certas comunidades, como as dos índios amazónicos, para exemplificarem estádios ideais de uma resistência substituta da nossa. Mas a tendência não é apenas no sentido da substituição da noção de resistência como rejeição de bens para uma noção menos simplista de resistência como domesticação ou adaptação. Verifica-se outra mudança no sentido de a noção de resistência como domesticação ser, ela própria, desprezada e substituída por uma nova noção que se desliga totalmente do tema da resistência, uma noção de apropriação que concebe os consumidores como mais activos e, sobretudo, mais positivamente interventivos. Generalizada a concepção das mercadorias como podendo sofrer recontextualizações singulares através da sua apropriação pelos sujeitos, o consumo de bens apresenta novas possibilidades de estudo enquanto idioma para o desenvolvimento de relações sociais e produção de identidades. Os trabalhos de D. Miller (1993) e J. Carrier (1995c) são bons exemplos de análises que explicitam estratégias diversas pelas quais os consumidores se apropriam de bens disponíveis no mercado.

Unwrapping Christmas é uma obra colectiva editada por Miller (1993) que "desembrulha" o festival de Natal, em primeiro lugar, porque documenta a sua existência actual através do mundo. Reúne ensaios focando o Natal em Inglaterra, nos Estados Unidos, na Suécia, no Japão, na Trindade e numa comunidade esquimó do Alasca. Fica evidente o sucesso global da celebração de Natal que conquistou quer áreas cristãs mais ou menos remotas, quer grupos de outras religiões. Por outro lado, a diversidade de Natais analisados sugere uma reavaliação da presumida expansão e adopção global do Natal anglo-americano. Os ensaios, no seu conjunto, demonstram que não se pode predizer de que modo uma determinada versão de Natal será transformada 
aquando do seu restabelecimento em novo contexto, tornando evidente que a sua apropriação pelos sujeitos é criativa e variada. Depois, a obra também "desembrulha" o Natal na "Introdução" escrita por Miller, onde, atendendo à universalidade da celebração e sua simultânea heterogeneidade, se formula uma teoria do Natal. Procura-se compreender a natureza fundamental do Natal através de um exercício de antropologia comparada que atende quer à diversidade de Natais recentemente estabelecidos no mundo, quer aos antecedentes muito antigos do Natal europeu. O Natal moderno surge como o resultado sincrético de três festivais pré-cristãos e da emergência da idealização da família nuclear pelo cristianismo. A família e o materialismo são os motivos dominantes e recorrentes que o sincretismo da celebração permite terem uma extensão global e um significado local. $\mathrm{Na}$ fórmula mais próxima da ocidental, o Natal é o festival da família pelo qual as mercadorias são apropriadas e incorporadas na sociabilidade do lar como presentes. Noutras fórmulas, o idioma da sociabilidade pode não se confinar à unidade básica da família e abarcar mais amplas sociabilidades, tornando-se um emblema de noções cosmológicas ou de "moralidades" objectivadas no "espírito de Natal". Este, em todos os casos, é o veículo que transmuta o materialismo como morte da vida social em sociabilidade pura. Entendido como potencial morte social, o materialismo é aplacado e ressocializado pelo Natal, que o transforma num veículo para a vida social através da transformação das mercadorias em presentes. A apropriação de mercadorias é um momento central do ritual anual do Natal.

Na obra Gifts and Commodities, igualmente tributária da noção de apropriação, Carrier (1995c) começa por analisar o movimento histórico da produção e circulação no Ocidente desde 1700, procurando perceber como esse movimento afectou as relações das pessoas com os objectos. O argumento histórico central é que a expansão do capitalismo industrial e comercial significou o expandir de relações distanciadas com os objectos. Tal expansão, porém, não esbate a necessidade de as pessoas continuarem a deter os seus objectos enquanto possessions - i. e., como objectos particulares e específicos - e de os transaccionarem no interior de relações pessoais e personalizadas. Tais necessidades tornam-se até mais prementes na nossa sociedade, dado o carácter anónimo das mercadorias e a sua inadequação, enquanto tal, a serem usadas em transacções no interior de relações pessoais. A solução é concretizar processos de apropriação das mercadorias através dos quais são convertidas em possessions. Por outro lado, a crescente impessoalidade nos modos de produção e comercialização capitalistas é concomitante com a emergência de construções culturais que distinguem e radicalmente opõem as esferas da economia e da sociedade, ou o domínio impessoal e utilitário do trabalho e o domínio pessoal e afectivo da família. Esta oposição é permeada em termos vivenciais mas ideologicamente radicalizada, simultaneamente reflectindo e moldando o entendimento das pessoas sobre os objectos. Dada esta construção cultural, 
as mercadorias "em bruto" disponibilizadas pela economia são apreendidas como impróprias para uso no domínio das relações pessoais da família e dos amigos. Para se tornarem adequadas, as mercadorias anónimas têm de ser apropriadas e transformadas em objectos específicos que traduzam o tipo de relações aí existentes. Cozinhar as refeições para a família, fazer as compras para essa família ou festejar o Natal são algumas das formas de realizar essa apropriação. Acerca do Natal moderno, Carrier (1995c) ${ }^{13}$ defende que ele se caracteriza pela compra e oferta de bens dentro da família nuclear e áreas adjacentes, tendo emergido com a expansão do capitalismo industrial e comercial sensivelmente a partir do meio do século XIX. A festa de Natal e as suas compras constituem um dos meios de transmutar as mercadorias anónimas disponíveis no mercado em possessions específicas e particulares, usando-as para criar e recriar relações pessoais. ${ }^{14}$

Regressando aos desenvolvimentos da antropologia do consumo, as novas tendências sentem-se também noutras linhas de pesquisa. A crítica da dicotomia entre presente e mercadoria inaugurada por Appadurai (1986) prossegue e reflecte-se, inclusivamente, numa nova focagem da cultura material cujos estudos enfatizam o significado social da mercadoria (Brewer e Porter 1993; Slater 1997), demonstrando o quão restritiva foi aquela oposição para a nossa capacidade de tomar os bens de massa como parte integrante da cultura moderna. Vendo-os como a cultura material da sociedade industrial, é possível concebê-los como podendo objectivar relações sociais e/ou servirem de mediadores a valores e sentimentos. A mesma linha de crítica à velha dicotomia desenvolve-se, por outro lado, no sentido do reexame das formas de troca pré e pós-coloniais, conduzindo à crítica dos modelos evolutivos e duais de troca pela demonstração mais de continuidades que de rupturas. Os textos reunidos na obra editada por Humphrey e Hugh-Jones (1992) contribuem para reposicionar a troca directa, desligando-a da sua caracterização como troca primitiva. O artigo mais radicalmente subversivo é o de Gell (1992), que defende que na Melanésia a mercadoria como meio de troca é anterior ao colonialismo. $\mathrm{O}$ artigo começa com a afirmação estrondosa de que a forma clássica de troca de presentes - a que chama reprodutiva porque usada na reprodução social interna do grupo - é melhor compreendida se percebida como derivada do comércio intertribal de mercadorias. A mercadoria para troca era uma característica-chave do comércio pré-colonial na região. As trocas intragrupo estão sujeitas a constrangimentos que contrastam com a liberdade existente nas trocas intertribais, que os homens em particular utilizam potenciando os seus

13 Carrier é autor de um dos capítulos incluído no Unwrapping Christmas editado por Miller (Carrier 1993).

14 Este trabalho de Carrier (1995c) traduz também uma crítica consistente à ideia das puras relações de mercado como pressuposto do consumo moderno. 
elementos de fama e perigo. Em certas circunstâncias, como no pagamento de compensações matrimoniais, a troca reprodutiva aplicou os modelos desenvolvidos na esfera do comércio externo.

Em conjunto, a nova ênfase na cultura material e a crítica aos modelos duais de troca reforçam a agora evidente percepção das variações nos modos de posse e uso de mercadorias. A contextualização de processos particulares de apropriação de mercadorias reforça a aceitação de formas de troca e consumo mais diversificadas e contingentes. O contributo dessas contextualizações pode ser exemplificado pela obra de N. Thomas (1991) Entangled Objects, dedicada ao estudo do encontro colonial no Pacífico. Não sendo um estudo do consumo, ao elucidar as condições e enredos locais relativos à variedade de atitudes perante os produtos europeus, esta monografia demonstra como a diversidade de sistemas de troca conduz a diferentes regimes de consumo. Desfaz-se a ideia dos povos do Pacífico como enganados pelos colares de contas dos europeus e fica demonstrado o actual uso do consumo como meio de expressão de noções cosmológicas fundamentais e criação de novas formas culturais.

Resultante destes desenvolvimentos e seu entrecruzamento, um último tópico de pesquisa emergente são as "compras". Encaradas como fenómeno cultural, as compras passam a merecer atenção por si mesmas. Nelas, as pessoas concretizam experiências e são guiadas por objectivos que estão muito para além do acto instrumental da compra efectuada. Importa sublinhar que esta abordagem do "ir às compras" é outra forma de dar corpo à percepção dos consumidores como agentes sociais em relação aos quais é pertinente compreender o que fazem e porque o fazem; para além disso, esta abordagem tem subjacente o reconhecimento da importância de concretizar estudos sobre as práticas efectivas dos consumidores, procedendo a pesquisas qualitativas que concretizam o tal estudo mais fenomenológico do consumo. ${ }^{15}$

Traduzindo a complexidade social para que as compras podem remeter, o interesse pelo tópico desdobra-se em várias vertentes. Uma delas elege os novos "sítios de consumo", sobretudo centros comerciais, como foco de análise e procura elucidar as relações sociais implicadas no acto de aí "ir às compras". Para Shields (1992a), ${ }^{16}$ o centro comercial é um locus de interacção social equiparável ao mercado enquanto lugar de encontro; apesar de privado, ele é transformado em espaço público pelas práticas sociais nele concretizadas pelos

15 Contudo, ainda é possível encontrar estudos onde as "compras" são abordadas como indício da decadência ocidental, insistindo-se na sedução enganadora da mercadoria (Bauman 1993).

16 A análise de Shields sobre os centros comerciais faz-se em dois capítulos da obra colectiva por ele editada, Lifestyle Shopping (Shields 1992b), cuja temática de conjunto é a mesma, mas que foca também outros sítios de consumo e estudos de caso relativos a Inglaterra, Estados Unidos, Canadá, Austrália, Japão e Singapura. 
seus consumidores. ${ }^{17}$ Outra possibilidade é abordar as compras em termos de estudos de género e sexualidade (Reekie 1993; Mort 1996), ou relacioná-las com a construção de várias identidades (Chaney 1996; Falk e Campbell 1997). Nesta problemática, uma abordagem a destacar é a defendida pelos dois editores da obra colectiva The Shopping Experience (Falk e Campbell 1997) na sua "Introdução". ${ }^{18}$ Para os autores, a construção do "eu" na contemporaneidade não está condenada à fragmentação e incoerência, sendo um processo reflexivo capaz de incorporar mudanças sem pôr em causa a continuidade do "eu". Importa, portanto, evitar noções simplistas sobre a autoconstrução do sujeito pelo processo de aquisição de bens. Um esquema demasiado mecânico conduz a ver as pessoas como "comprando" uma identidade pronta a usar e tem o efeito de reduzir as identidades dos consumidores a "identidades sociais". Para alterar tal percepção das coisas, há que perceber que a autoconstrução identitária pelas compras não é redutível à aquisição e exibição de bens. O processo inclui uma componente imaginária, experimental e reflexiva que se concretiza pela interacção com os sítios de consumo e com as mercadorias, mesmo quando não se actualizam actos de compra. Os actos reflexivos que ocorrem perante os bens desencadeiam séries de experiências sensoriais e acções imaginárias com as quais o sujeito se coloca várias questões - isto é para mim?, isto pode ser para mim?, gostaria de ser assim? - que são elas próprias já actos de autoconstrução. As compras podem ser fundamentais para perceber o processo de construção identitária na contemporaneidade.

Uma terceira vertente de análise junta as três dimensões: compras, identidade e lugar, como ilustra o título da obra Shopping, Place and Identity (D. Miller et al. 1998), que elege dois centros comerciais londrinos como âmbito empírico de estudo (Duarte 2002). As compras são tratadas como tendo que ver com redes de relações sociais, mormente familiares e de amizade, cuja manutenção pede constantes e consideráveis despesas de consumo. Insistindo no carácter processual e relacional da construção identitária, as identidades contemporâneas são concebidas como múltiplas e contestadas, discursivamente constituídas pelas narrativas do "eu", construídas em relação a "outros" socialmente significantes e articuladas através de relações com pessoas, bens e lugares particulares. As narrativas identitárias são construídas pelos discursos com que as pessoas se delineiam a si mesmas através de relações valorativas estabelecidas com tipos particulares de bens e de lugares. Os sítios das compras podem ser desses lugares, onde parâmetros particulares de identidade, como a etnicidade, o género ou a classe, são (re)construídos pela adição de distinções específicas

17 A aproximação aos centros comerciais por parte da autora do presente texto, como parte do trabalho exploratório da pesquisa Experiências de Consumo: Estudos de Caso no Interior da Classe Média (2009), conduziu a constatações de teor bastante semelhante (Duarte 2003).

18 No conjunto, os capítulos da obra fornecem exercícios de reflexão e pesquisa etnográfica sobre diversos sítios de compras. 
ou valorizações diferenciadas de tais sítios e das experiências aí vividas. A criação de um sentido particular de classe, ou de etnicidade, ou de género, objectifica-se através de várias práticas, entre elas a das compras, e estas podem encontrar no centro comercial - ou noutro sítio de compras - um meio específico para a sua objectificação.

Por fim, merece ainda destaque a teoria interpretativa das compras de D. Miller (1998), A Theory of Shopping, onde, com o apoio de uma etnografia aprofundada e focando as compras de aprovisionamento regular do lar e da família, se salienta os seus fundamentais aspectos normativos na contemporaneidade. A etnografia permitiu constatar que, na maioria dos lares, o acto de ir às compras não é orientado para as pessoas que o realizam, mas pensado em função de uma relação entre o comprador e outro sujeito particular - o marido, a filha, a mãe - presente, desejado ou imaginado no lar; por outro lado, a tarefa das compras é valorizada positivamente, não sendo vista como opressiva, ainda que exigindo esforço e dedicação, nem como algo passivo da parte do comprador. A interpretação sugerida é que as compras são actos de amor. Mais exactamente, o amor como ideologia é objectificado através de práticas diárias de atenção e cuidado para com os outros, entre as quais o "ir às compras" tem um papel central. ${ }^{19}$ Simultaneamente, o comprador não está apenas a comprar bens para os outros, mas a tentar influenciar esses outros para que se tornem as pessoas adequadas ao que foi comprado. Miller constata ainda que a maioria das compras apresenta o traço de ser moralmente marcada pela sobriedade e moderação, podendo-se definir o ethos das compras como a poupança. É uma noção mais moral do que funcional, já que poupar não significa necessariamente gastar menos, antes remetendo para estratégias particulares com cuja adopção as pessoas legitimam as suas práticas e associam a si mesmas conotações de respeitabilidade e correcção resultantes de se verem como pessoas poupadas. A poupança deve ser vista, não como um instrumento de medida para gastar menos ou estritamente relacionada com o orçamento disponível, mas como o centro de quase todas as compras contemporâneas, via pela qual um acto de despesa é transformado no seu oposto.

Em contraste flagrante com a prática observada está, porém, o que se pode chamar o discurso das compras. Quando as pessoas falam delas como um tópico geral e abstracto - não das suas compras -, verifica-se uma admirável uniformidade na consideração dessa actividade como larga ou completamente devotada à auto-indulgência, à extravagância sem constrangimentos, ao excesso. Para resolver esta discrepância flagrante entre discurso e prática das compras, Miller

19 Não se trata aqui do ideal romântico do amor, mas do amor como o fundamento ideológico das relações entre os membros da família que, na prática, se traduz numa "tecnologia do cuidar"; Miller (1998) também encontrou práticas de compras não relacionadas com o amor, mas antes com a autosatisfação, a tradição, o hedonismo... Defende, contudo, que o amor constitui o contexto e a motivação dominantes da actual prática das compras (Duarte 2002). 
(1998) desenvolve a teoria das compras como sacrifício, destacando a evidência de compras e sacrifício terem a uni-los o facto de ambos representarem momentos-chave na vida das pessoas em que o trabalho da produção é transformado em processo de consumo. O sacrifício é sempre um acto de despesa pelo qual algo de material é consumido, mas por meio do qual se atingem benefícios que nada têm de materiais. Por analogia, as compras são vistas como um acto que transforma a despesa num ritual de devoção para com os membros da família, reafirmando a força transcendente do amor. A estrutura comum tem três estádios. O primeiro corresponde a uma visão de excesso: ambos os discursos - compras e sacrifício - representam uma fantasia da despesa extrema e do consumo como dissipação. A este nível, as compras são a objectificação de uma forma de liberdade absoluta que fantasia a sua não-ligação a qualquer relação social ou obrigação. No segundo estádio são negados os discursos anteriores e feita a atribuição de objectivos transcendentes ao consumo realizado: no sacrifício, a constituição do divino pelo estabelecimento de relações com os deuses; nas compras, a idealização da sua prática como actividade santificada pela transformação da despesa em poupança. Esta não deve ser entendida como um meio para atingir um fim - poupar para a velhice ou para quando estivermos desempregados -, mas como um fim em si mesma, já que é através dela que se cria um objectivo transcendente para a vida. A poupança é instrumental na criação do lar como objecto transcendente de devoção, sendo, portanto, a objectificação de um valor mais alto do que ela própria. No terceiro estádio, o transcendente já alcançado é usado para sancionar as relações sociais do grupo. Nas compras, com o consumo já santificado, os bens podem ser comprados e distribuídos pelos membros do lar como expressão geral de amor, procurando-se transformá-los nos sujeitos desejados.

Como comentários finais sobre os desenvolvimentos da antropologia do consumo, quero deixar assinalada quer a proliferação actual de estudos e contextualizações diversas do fenómeno, quer a intensificação das pesquisas etnográficas e a crescente percepção da sua necessidade. Assegurar a focagem da diversidade no interior do consumo de massa e correlativas possibilidades diversas de apropriação activa pelos sujeitos é fundamental, quer para compreender um processo de construção cultural central da contemporaneidade, quer para a ultrapassagem definitiva do primitivismo latente na disciplina (Miller 1995b). Neste sentido, pode afirmar-se que a emergência e maturidade da antropologia do consumo contribuíram para a transformação da natureza da disciplina como um todo. Perceber o consumo de massa como potencial fonte de diversidade requer que as modalidades particulares de consumo praticadas em cada região/sociedade passem a ser olhadas como variantes, diferentes mas todas elas igualmente autênticas, da sociedade de consumo de massa que constitui a Modernidade. Constituir o consumo de massa como objecto de estudo 
antropológico implica, portanto, o reconhecimento de que a cultura não é um atributo que se ganha ou perde, mas um processo, pelo que o amadurecimento da antropologia do consumo permitiu que a disciplina pudesse deixar de se dedicar à promoção da exclusão de algumas sociedades relativamente aos produtos da sociedade industrial, passando de uma visão que projectava os seus próprios desejos para uma outra, capaz de entender o consumo como gerador de novas formas culturais.

Reconhecendo que o consumo de massa não é meramente a adopção passiva de práticas incaracterísticas e idênticas, os antropólogos podem dar conta das formas culturais que crescentemente empregam o consumo como meio de expressão, bem como das construções sociais de valor subjacentes às práticas de consumo. Definindo como seu objectivo o documentar de respostas diversas às possibilidades de consumo, dando conta das esferas de relações sociais mais e menos íntimas que usam a mercadorização como linguagem ou a recusam, a antropologia assume a opção de não se tornar mera elegia da suposta perda de especificidade cultural, antes orientando os seus esforços para uma tarefa mais profícua: a descoberta e compreensão de alguns dos elementos mais significativos participantes do processo de construção societal na contemporaneidade. Olhado como tal, o consumo justifica todo o actual interesse no seu estudo.

\section{BIBLIOGRAFIA}

ABU-LUGHOD, L., 1990, "The romance of resistance: tracing transformations of power through Bedouin women”, American Ethnologist, 17 (1): 41-55.

APPADURAI, A., 1986, "Introduction: commodities and the politics of value", em A. Appadurai (ed.), The Social Life of Things: Commodities in Cultural Perspective. Cambridge, Cambridge University Press, 3-63.

BAUMAN, Z., 1993, "From pilgrim to tourist - or a short history of identity", em S. Hall e P. du Gay (eds.), Questions of Cultural Identity. Londres, Sage Publications, 18-36.

BENSON, S., 1986, Counter Cultures: Saleswomen, Managers and Costumers in the American

Department Stores, 1890-1940. Urbana e Chicago, University of Illinois Press.

BOURDIEU, P., 1979, La distinction: critique sociale du jugement. Paris, Les Editions de Minuit.

BREWER, J., e R. PORTER (eds.), 1993, Consumption and the World of Goods. Londres, Routledge.

CAPLOW, T., 1982, "Christmas gifts and kin networks", American Sociological Review, 47: 383-392.

CARRIER, J., 1993, “The rituals of Christmas giving”, em D. Miller (ed.), Unwrapping Christmas. Oxford, Oxford University Press, 55-74. 
CARRIER, J., 1995a, "Introduction", em J. Carrier (ed.), Occidentalism: Images of the West. Nova Iorque, Oxford University Press, 1-32.

—, 1995b, "Maussian Occidentalism: gift and commodity systems", em J. Carrier (ed.), Occidentalism: Images of the West. Nova Iorque, Oxford University Press, 85-108.

—, 1995c, Gifts and Commodities: Exchange and Western Capitalism Since 1700. Londres, Routledge.

CERTEAU, M. de, 1984, The Practice of Everyday Life. Berkeley e Los Angeles, University of California Press.

CHANEY, D., 1983, "The department store as a cultural form", Theory, Culture and Society, 3 (1): 22-31.

—, 1996, Lifestyles. Londres, Routledge.

CHUA, B.H., 1992, "Shopping for women's fashion in Singapore”, em R. Shields (ed.), Lifestyle Shopping. Londres, Routledge, 114-135.

DOUGLAS, M., e B. ISHERWOOD, 1978, The World of Goods. Londres, Allen Lane.

DUARTE, A., 2002, "Daniel Miller e a antropologia do consumo", Etnográfica, 6 (2): 367 $-378$.

—, 2003, "O centro comercial, o espaço público e os cidadãos", Trabalhos de Antropologia e Etnologia, 43 (1-2): 75-85.

—, 2009, Experiências de Consumo: Estudos de Caso no Interior da Classe Média. Porto, Editora da Universidade do Porto.

FALK, P., e C. CAMPBEll (eds.), 1997, The Sopping Experience. Londres, Sage Publications.

FRIEDMAN, J., 1990, "Being in the world: globalization and localization", em M. Featherstone (ed.), Global Culture: Nationalism, Globalization and Modernity. Londres, Sage Publications, 31 1-328.

GEIST, J.-F., 1983, Arcades. Cambridge, The MIT Press.

GELL, A., 1992, "Inter-tribal commodity barter and reproductive gift-exchange in old Melanesia”, em C. Humphrey e S. Hugh-Jones (eds.), Barter, Exchange and Value. Cambridge, Cambridge University Press, 142-168.

HART, K., 1982, “On commoditization”, em E. Goody (ed.), From Craft to Industry. Cambridge, Cambridge University Press, 38-49.

HAUG, W., 1986, Critique of Commodity Aesthetics: Appearance, Sexuality and Advertising in Capitalist Society. Cambridge, Polity Press.

HEATH, D., 1992, "Fashion, anti-fashion and heteroglossia in urban Senegal", American Ethnology, 19: 19-33.

HUGH-JONES, S., 1992, "Yesterday's luxuries, tomorrow's necessities: business and barter in northwest Amazonia”, em C. Humphrey e S. Hugh-Jones (eds.), Barter, Exchange and Value. Cambridge, Cambridge University Press, 42-74.

HUMPHREY, C., e S. HUGH-JONES (eds.), 1992, Barter, Exchange and Value. Cambridge, Cambridge University Press.

JUles-rosette, B., 1990, Terminal Signs: Computers and Social Change in Africa. Berlim, Mouton de Gruyer.

LAERMANS, R., 1993, "Learning to consume: early department stores and the shaping of modern consumer culture 1860-1914", Theory, Culture and Society, 10 (4): 79-102.

LANCASTER, W., 1994, The Department Store: A Social History. Londres, Pinter.

MARX, K., 1979 [1867], O Capital. Lisboa, Edições 70. 
MAUSS, M., 2001 [1923-1924], Ensaio sobre a Dádiva. Lisboa, Edições 70.

McCRACKEN, G., 1988, Culture and Consumption. Bloomington, Indiana University Press.

McKENDRICK, N., J. BREWER, e J. PLUMB, 1983, The Birth of a Consumer Society. Londres, Hutchinson.

MILler, D., 1987, Material Culture and Mass Consumption. Oxford, Basil Blackwell.

—, 1988, "Appropriating the state on the council estate", Man, 23: 353-372.

— 1992, "The young and the restless in Trinidad: a case of the local and the global in mass consumption”, em R. Silverstone e E. Hirsch (eds.), Consuming Technologies. Londres, Routledge, 163-182.

— (ed.), 1993, Unwrapping Christmas. Oxford, Oxford University Press.

- (ed.), 1995a, Acknowledging Consumption: A Review of the Studies. Londres, Routledge.

—, 1995b, "Consumption studies as the transformation of anthropology", em D. Miller (ed.), Acknowledging Consumption: A Review of the Studies. Londres, Routeledge, 264-295.

_-, 1995c, "Consumption and commodities", Annual Reviews Anthropology, 24: 141-161.

—, 1997, "Coca-Cola: a black sweet drink from Trinidad”, em D. Miller (ed.), Material Cultures. Londres, University College London Press.

—, 1998, A Theory of Shopping. Nova Iorque, Cornell University Press.

MILler, D., et al., 1998, Shopping, Place and Identity. Londres e Nova Iorque, Routledge.

MILler, M. B., 1981, The Bon Marché: Bourgeois Culture and the Department Store 1869-1920.

Princeton, Princeton University Press.

MINTZ, S., 1985, Sweetness and Power: The Place of Sugar in Modern History. Nova Iorque, Penguin.

MORT, F., 1996, Cultures and Consumption: Masculinities and Social Space in Late Twentieth-Century Britain. Londres, Routledge.

MUKERJI, C., 1983, From Graven Images. Nova Iorque, Columbia University Press.

PRETECEILle, E., e J.-P. TERrAil, 1985, Capitalism, Consumption and Needs. Oxford, Basil Blackwell.

REEKIE, G., 1993, Temptations: Sex, Religion and the Department Store. St. Leonards, George Allen and Unwin.

ROWLANDS, M., 1995, “The material culture of success”, em J. Friedman (ed.), Consumption and Identity. Londres, Harwood Academic, 147-166.

SAÏD, E., 1978, Orientalism. Harmondsworth, Penguin.

SAHLINS, M., 1974 [1972], Stone Age Economics. Londres, Tavistock.

— 1976, Culture and Practical Reason. Chicago, University of Chicago Press.

SASSATElli, R., 2007, Consumer Culture: History, Theory and Politics. Londres, Sage Publications.

SHIELDS, R., 1992a, "The individual, consumption cultures and the fate of community", em R. Shields (ed.), Lifestyle Shopping: The Subject of Consumption. Londres, Routledge, 99-113.

— (ed.), 1992b, Lifestyle Shopping: The Subject of Consumption. Londres, Routledge.

SLATER, D., 1997, Consumer Culture and Modernity. Cambridge, Polity Press.

TAussig, M., 1980, The Devil and Commodity Fetishism in South America. Chapel Hill, NC, University North Carolina Press.

THOMAS, N., 1991, Entangled Objects. Cambridge, MA, Harvard University Press.

TOBIN, J. (ed.), 1992, Re-made in Japan. New Haven, CT, Yale University Press.

TREnTMANN, F. (ed.), 2006, The Making of Consumer: Knowledge, Power and Identity in Modern World. Oxford, Berg. 
VEBLEn, T., 1970 [1898], The Theory of the Leisure Class. Londres, George Allen and Unwin.

WILliAMS, R.H., 1982, Dream Worlds: Mass Consumption in Late Nineteenth-Century France. Berkeley, University of California Press.

The anthropology and the study of consumption: critical review of their relations and possibilities - Alice Duarte - Faculdade de Letras da Fundação Universidade do Porto, Portugal • alice_duarte@hotmail.com

The paper begins by placing in time the emergency of consumption as an area of anthropological investigation, seeking to expose the circumstances that made the establishment of an anthropology of consumption rather difficult. Next, following the development steps within that area of studies, the paper presents a selective synthesis of authors and works that, in any way, are making a change to a real concern on the study of consumption.

KEYWORDS: anthropology of consumption, critical review, Mauss, Marx, theories of consumption, regimes of consumption. 